\title{
LA RELACIÓN DE TRABAJO Y LA PROTECCIÓN DE LOS TRABAJADORES. UNA REVISIÓN DE LA NORMATIVA DE LA ORGANIZACIÓN INTERNACIONAL DEL TRABAJO DESDE LA PERSPECTIVA DE GÉNERO
}

\author{
THE EMPLOYMENT RELATIONSHIP AND LABOUR \\ PROTECTION.
}

A REVIEW OF THE RULE OF THE INTERNATIONAL LABOUR ORGANIZATION UNDER GENDER PERSPECTIVE

\section{BEATRIZ I. BARRADO SORIA}

Doctoranda del Programa del Doctorado de Derecho y Ciencias Sociales UNED

Resumen: La protección de los trabajadores es elemento esencial del mandato de la Organización Internacional de los Trabajadores, objetivo fundamental del Programa de Trabajo Decente y meta fijada por Naciones Unidas en su nueva Agenda 2030 para el Desarrollo Sostenible. Las políticas nacionales deben encaminarse a garantizar que todos trabajadores vinculados por una relación de trabajo reciban una adecuada protección de la ley. En este artículo se analiza la importancia de la relación de trabajo como medio para ofrecer protección jurídica a los trabajadores, por qué la falta de protección laboral agrava las desigualdades de los grupos más vulnerables y qué medidas específicas deben tomar los países para abordar con eficacia la dimensión de género. 
Abstract: The protection of workers is one of the core objectives of the International Labour Organization, fundamental objective of the Decent Work Agenda and target set by the United Nations in its new 2030 Agenda for Sustainable Development. National policies should aim to ensure that all workers in an employment relationship receive adequate protection of the law. This article discusses the relevance of the employment relationship as a means of providing legal protection to workers, why lack of labor protection aggravates inequalities of vulnerable groups and what specific policies countries must apply to effectively address the gender dimension.

Palabras claves: Organización Internacional del Trabajo, relación de trabajo, protección de los trabajadores, igualdad de género.

Keywords: International Labour Organization, employment relationship, labour protection, gender equality.

Sumario: I. Planteamiento de la cuestión. II. La protección de los trabajadores y el Programa del Trabajo Decente. III. La recomendación sobre la transición de la economía informal a la economía formal. IV. Los cuatro ámbitos de la protección de los trabajadores. Consideraciones relacionadas con la igualdad de género. 1. Salarios. 2. Tiempo de trabajo. 3. Seguridad y salud en el trabajo. 4. Protección de la maternidad.

Recepción original: 03/10/2016.

Aceptación original: 10/10/2016.

\section{PLANTEAMIENTO DE LA CUESTIÓN}

La Conferencia Internacional del Trabajo define la relación de trabajo como una noción jurídica de uso universal con la que se hace referencia a la relación que existe entre una persona, denominada el empleado o el asalariado (o, a menudo, el trabajador), y, otra persona, denominada el empleador, a quien aquélla proporciona su trabajo bajo ciertas condiciones, a cambio de una remuneración ${ }^{1}$.

A través de la relación de trabajo, independientemente de la manera en la que se haya definido, se crean derechos y obligaciones recíprocas entre el trabajador y el empleador. La existencia de una rela-

${ }^{1}$ La relación de trabajo, Informe V (1), Conferencia Internacional del Trabajo, 95. ${ }^{\mathrm{a}}$ reunión, Oficina Internacional del Trabajo, Ginebra, 2006, pág. 3. 
ción laboral es la condición necesaria para la aplicación de las leyes del trabajo y de la seguridad social a los trabajadores, y el medio de acceso a los derechos y beneficios asociados con el empleo. Es también el punto de referencia para determinar la naturaleza y la extensión de los derechos de los empleadores y de sus obligaciones con respecto de los trabajadores.

Junto con los derechos económicos -tales como remuneración, cotizaciones a la seguridad social o asignaciones-, el empleado goza de una serie de derechos relativos a su libertad y su dignidad, entre ellos, los derechos sindicales, derechos civiles y políticos, condiciones de trabajo justas y decorosas, no discriminación por razones de género y otras características personales respeto de su vida privada, y consideración frente a la necesitad de armonizar el trabajo y la familia. Además, el empresario no tiene derecho a indagar sobre la vida privada de los empleados, sus ideas políticas, su religión o su participación en actividades sindicales, y todos los empleadores y las empresas, así como las organizaciones de empleadores y de trabajadores, tienen la responsabilidad de combatir la discriminación en el lugar de trabajo, y promover la igualdad de género y la igualdad de remuneración por un trabajo de igual valor ${ }^{2}$.

La relación de trabajo es, por tanto, una figura jurídica de uso universal a través de la cual se reconoce a los trabajadores sus principales derechos y protecciones, y la mayoría de las normas internacionales de trabajo sobre protección de los trabajadores parten de ese mismo principio ${ }^{3}$.

La protección de los trabajadores y la ampliación de las medidas de protección laboral a todos los empleados es, además, un elemento esencial del mandato de la Organización Internacional del Trabajo (OIT). Desde su fundación, ha defendido la protección de los trabajadores y la garantía de los derechos fundamentales en el trabajo a tra-

2 ABC de los derechos de las trabajadoras y la igualdad de género, Oficina Internacional del Trabajo, Ginebra, 2008, págs. 56-58.

${ }_{3}$ El ámbito de la relación de trabajo, Informe V, Conferencia Internacional del Trabajo, 91. ${ }^{a}$ reunión, Oficina Internacional del Trabajo, Ginebra, 2003, pág. 2.

La protección de los trabajadores presenta facetas muy diversas en las que intervienen muchos actores e instituciones. Por lo general, conlleva la concesión de prestaciones de seguridad social destinadas a cubrir contingencias como enfermedad, incapacidad, vejez, maternidad y desempleo, riesgos para la salud y seguridad en el trabajo, igualdad de oportunidades en el acceso, y protección contra la discriminación y contra la inseguridad en el empleo y los ingresos. Protecciones que pueden estar vinculadas o no a la relación de trabajo y que su naturaleza puede cambiar en el transcurso del tiempo. La realidad es que sólo una minoría de la fuerza de trabajo mundial disfruta del conjunto de dichas prestaciones (Informe V, pág. 1). 
vés de sus políticas e instrumentos normativos. Ya en la Declaración de Filadelfia de 1944, se reconocía el objetivo de la Organización de fomentar programas que permitieran la extensión de medidas de seguridad social y la protección adecuada de los trabajadores en todas las ocupaciones ${ }^{4}$.

Con la adopción de la Declaración relativa a los principios y derechos fundamentales en el trabajo en 1998, todos los Miembros, desde el momento de su incorporación a la OIT, aun cuando no hayan ratificado los convenios fundamentales que los desarrollan de forma específica, quedan obligados a respetar y promover los principios y derechos fundamentales enunciados en la Constitución de la OIT y en la Declaración de Filadelfia. Principios y derechos fundamentales que incluirán a todos los trabajadores, aunque no se hallen en una relación de trabajo ${ }^{5}$.

En la mayoría de los países de la OIT, la regulación de la protección de los trabajadores se ha basado principalmente en el concepto universal de la relación de trabajo, que parte de la distinción que se hace entre trabajadores dependientes e independientes, también llamados autónomos o por cuenta ajena ${ }^{6}$.

${ }^{4}$ Declaración relativa a los fines y objetivos de la Organización Internacional del Trabajo, adoptada el 10 de mayo de 1944. «III. La Conferencia reconoce la obligación solemne de la Organización Internacional del Trabajo de fomentar, entre todas las naciones del mundo, programas que permitan: f) extender las medidas de seguridad social para garantizar ingresos básicos a quienes los necesiten y prestar asistencia médica completa; g) proteger adecuadamente la vida y la salud de los trabajadores en todas las ocupaciones».

${ }^{5}$ La Declaración de la OIT relativa a los principios y derechos fundamentales en el trabajo y su seguimiento, adoptada en 1998, establece claramente que estos derechos son universales y que se aplicarán a todas las personas en todos los países, independientemente del nivel de desarrollo económico. Menciona en particular a los grupos con necesidades especiales, tales como los desempleados y los trabajadores migrantes. La Conferencia Internacional del Trabajo así lo apunta: «La Declaración (ref. Declaración de 1998) no excluye de su campo de aplicación a los trabajadores que no se hallan en una relación de trabajo o que, dicho de otra manera, no tienen un empleador en el sentido estricto del término». El ámbito de la relación de trabajo, Informe V, Conferencia Internacional del Trabajo, 91. ${ }^{a}$ reunión, Oficina Internacional del Trabajo, Ginebra, 2003, pág. 5. Un estudio en profundidad de la Declaración de 1998 y su seguimiento es el de Bonet PÉREz, J. en Principios y derechos fundamentales en el trabajo: la declaración de la OIT de 1998, Universidad de Deusto, Bilbao, 1999.

${ }^{6}$ Aclarado en varias ocasiones por la OIT, el trabajo independiente o por cuenta propia en el marco de un arreglo contractual comercial o civil está por definición fuera del ámbito de la relación de trabajo. La relación de trabajo, Informe V (1), Conferencia Internacional del Trabajo, 95. ${ }^{\text {a }}$ reunión, Oficina Internacional del Trabajo, Ginebra, 2006, Anexo 2, Conclusión 1, pág. 74. 
Los debates de la Organización en los últimos años, se han centrado principalmente en la cuestión de la protección de los trabajadores dependientes basándose en el concepto de la relación de trabajo. Se han analizado las llamadas relaciones de trabajo encubiertas, ambiguas y triangulares, las formas atípicas de empleo y la economía informal. La desprotección jurídica y de hecho de los trabajadores dependientes, como consecuencia de los cambios sociales y económicos de los últimos años, parece haberse incrementado. Las variaciones en la estructura del mercado y organización del trabajo han dado lugar a modalidades de empleo cambiantes dentro y fuera de la relación de trabajo. Una consecuencia puede ser la indeterminación de saber si una persona es empleada o trabajador independiente. La aplicación deficiente de la ley puede dar lugar a situaciones de trabajadores que son empleados, pero que no cuentan con la protección que ofrece una relación de trabajo. Esta modalidad de falso trabajo por cuenta propia, representativo de economías menos estructuradas, es cada vez más habitual en países con mercados de trabajo bien organizados ${ }^{7}$.

La OIT no ha dejado de insistir en la necesidad de atender a los grupos más vulnerables como los trabajadores migrantes, desempleados, mujeres y niños, y advierte que la falta de protección legal de los trabajadores dependientes, agravaba las desigualdades que suelen producirse entre mujeres y hombres en el ámbito laboral. Como primera medida, comienza a prestar más atención a las cuestiones de género, puesto que el mandato de la OIT de búsqueda de la justicia social y promoción de la igualdad de oportunidades en el mundo del trabajo, está consagrado en su Constitución y debe reflejarse en toda la labor de la Organización ${ }^{8}$.

En los años 1997 y 1998, la Conferencia examinó en profundidad el trabajo en régimen de subcontratación con la finalidad de adoptar un convenio y una recomendación que protegiera algunas categorías de trabajadores desprovistas de amparo laboral, como las relaciones de trabajo triangulares. Si bien la falta de consenso impidió adoptar un instrumento al respecto, la Comisión del Trabajo en Subcontratación de la Conferencia precisó que un tema de futura discusión debería ser la situación de los trabajadores dependientes privados de protección laboral, con miras a la posible adopción de un convenio complementado por una recomendación y de la celebración de reu-

${ }^{7}$ El ámbito de la relación de trabajo, Informe V, Conferencia Internacional del Trabajo, 91. ${ }^{a}$ reunión, Oficina Internacional del Trabajo, Ginebra, 2003, págs. 19-20.

${ }_{8}^{8}$ Declaración relativa a los fines y objetivos de la Organización Internacional del Trabajo, adoptada el 10 de mayo de 1944, párrafo II. 
niones de expertos para identificar a estos trabajadores y los medios adecuados para su protección ${ }^{9}$.

En mayo de 2000, se celebra en Ginebra la reunión de composición tripartita de expertos sobre los trabajadores en situaciones en las cuales necesitan protección ${ }^{10}$. Los debates se basaron en estudios realizados por países que tenían como objeto determinar las principales situaciones en las que los trabajadores carecían de protección suficiente, sus problemas derivados y la sugerencia de medidas correctivas.

La Reunión de expertos destacó que los cambios en la naturaleza del trabajo habían dado lugar a situaciones en las que el ámbito de la relación de trabajo, no se ajustaba a las realidades laborales y que se había producido una tendencia a la desprotección jurídica o de hecho de los trabajadores, que deberían estar protegidos por las leyes de trabajo ${ }^{11}$. La falta de protección en algunas categorías de trabajadores iba en aumento.

En muchos países el proceso de la mundialización ${ }^{12}$ unido a los cambios tecnológicos, la transformación y reestructuración de la organización y funcionamiento de las empresas, y un entorno económico muy competitivo, había contribuido al crecimiento del empleo y al nacimiento de nuevas formas de trabajo. Sin embargo, en los llamados países en desarrollo y países con economías en transición, sus efectos habían sido la reducción y deterioro de las condiciones de trabajo y el aumento del desempleo, de la economía informal y del

${ }^{9}$ La Conferencia Internacional del Trabajo adoptó la Resolución relativa a la posible adopción de instrumentos internacionales para la protección de los trabajadores en las situaciones identificadas por la Comisión del trabajo en Subcontratación (86. ${ }^{\text {a }}$ reunión, 1998).

${ }^{10}$ Reunión de expertos sobre los trabajadores en situaciones en las cuales necesitan protección. Organización Internacional del Trabajo, Ginebra, 15-19 de mayo de 2000, Informe del debate. MEWNP/2000/4 (Rev.) y Declaración conjunta de los expertos participantes en la Reunión de expertos en situaciones en las cuales los trabajadores necesitan protección.

${ }^{11}$ Los expertos empleadores que participaron en el debate, discrepaban alegando que los alcances de esta tendencia no estaban demostrados. En la discusión se señala que los empleadores sufren el desafío de sobrevivir en una economía competitiva y que legítimamente buscan soluciones viables entre las diversas formas de empleo que regula la ley.

12 Para un análisis del trabajo en la globalización, véase FuJII, G. y Ruesga, S., El trabajo en un mundo globalizado, Ediciones Pirámide, Madrid, 2004, págs. 18 y ss. Se puede consultar además, la Comisión Mundial sobre la Dimensión Social de la Globalización, que fue instituida por OIT en febrero de 2002. La Comisión es un organismo independiente creado para dar respuesta a las necesidades de las personas que resultan de los cambios sin precedentes que la mundialización provoca en sus vidas, sus familias y en la sociedad donde viven. 
trabajo no declarado o encubierto. Los cambios se atribuyeron también a las crisis financieras, la deuda externa, las privatizaciones, las migraciones, el crecimiento del sector terciario, el incremento de la participación de las mujeres en el trabajo y la mejor cualificación de los jóvenes trabajadores.

Las consecuencias de la desprotección son muchas, y se manifiestan en todos los sectores de la actividad. En primer lugar, afecta a los trabajadores y a sus familias, pero también puede tener efectos contraproducentes contra las empresas. La inexistencia de derechos y garantías aumentan el desapego del empleado, afectando a la productividad y competitividad de la misma. La desprotección conlleva también el descuido de la salud y seguridad del trabajador, al igual que su formación, afectando de igual manera en la empresa. Por último, tiene también consecuencias negativas en la sociedad y en los gobiernos.

Los estudios pusieron de relieve la especial posición de desprotección de las mujeres en la relación de trabajo. Los problemas de desigualdades que sufren las trabajadoras en el acceso y ocupación al empleo tienden a acentuarse en estas situaciones, y suele existir una concentración de personal femenino en el trabajo no protegido debido a que los cambios afectan más a las mujeres que a los hombres.

La Reunión convino que los países debían adoptar una política nacional que incluyera, de forma periódica, la revisión y adaptación de la regulación de la relación de trabajo en sus legislaciones de acuerdo con la realidad del empleo y siempre en colaboración con los interlocutores sociales. Las políticas nacionales podrían incluir aspectos como la información clara a empleadores y trabajadores acerca de las relaciones de trabajo, y la distinción entre trabajador dependiente e independiente, la efectiva protección de los trabajadores, la lucha contra el encubrimiento de la relación de trabajo, la no interferencia a las contrataciones comerciales o de trabajo independiente, y el acceso a mecanismos adecuados de solución de conflictos para determinar la condición jurídica de los trabajadores. Propone además, que la Conferencia adopte un convenio y una recomendación ${ }^{13}$.

13 Declaración conjunta de los expertos participantes en la Reunión de expertos en situaciones en las cuales los trabajadores necesitan protección, Organización Internacional del Trabajo, Ginebra, 2000, puntos 5, 6 y 7. En palabras de GIL y GIL, J. L., la OIT, además de hacer frente al fenómeno estructural de la globalización, ha tratado de dar una respuesta adecuada a la crisis financiera y económica, y a diferencia de otras organizaciones internacionales como el Banco Mundial (BM), el Fondo Monetario Internacional (FMI) o la Organización Mundial de Comercio (OMC), que proponen una reforma estructural del mercado de trabajo para hacerlo más flexible y 
En el año 2003, la Conferencia continúa el debate sobre la relación de trabajo y la protección de los trabajadores. Se insiste en la necesidad de garantizar que los acuerdos en virtud de los cuales un trabajador presta sus servicios se encuadren en un marco jurídico adecuado $^{14}$.

Se analizan las relaciones de trabajo ambiguas y las relaciones de trabajo disfrazadas o encubiertas, con las que se elude el pago de impuestos, las cargas de la seguridad social y se priva de la protección laboral al trabajador ${ }^{15}$.

En muchos países, la legislación es ambigua o muy restrictiva y a esto se suma la inobservancia de la ley y también la falta de medidas para velar por su cumplimiento. Con estas condiciones, es difícil evitar las infracciones o proteger los derechos de los trabajadores. Los problemas de incumplimiento y falta de aplicación de la ley son mayores en la economía informal ${ }^{16}$.

Para que la ley sea eficaz, en primer lugar habría que esclarecer su campo de aplicación, completarlo y precisarlo. En segundo lugar, debería existir un compromiso político del Estado para garantizar su observancia y el funcionamiento eficaz de los mecanismos e instituciones que existen para hacer cumplir la legislación del trabajo, en

adaptable a las exigencias de la economía, se ha centrado en la dimensión social de la crisis, la coherencia entre la política económica y social y la importancia de considerar el empleo y la protección como ejes de las políticas públicas. «Trata, pues, de conjugar el desarrollo económico, los derechos del trabajo y la protección social. Aun nadando a contracorriente, aspira a conferir legitimidad a la globalización, dotándola de unos valores éticos». GIL y GIL, J. L., "Globalización y empleo: Propuestas de la OIT para un desarrollo sostenible», Revista Doctrinal Aranzadi Social, núm. 11, 2014, pág. 21.

${ }_{14}$ El ámbito de la relación de trabajo, Informe V, Conferencia Internacional del Trabajo, 91. . reunión, Oficina Internacional del Trabajo, Ginebra, 2003.

15 La relación de trabajo encubierta se produce cuando un empleador considera a una persona que es un empleado como si no lo fuese, con el fin de ocultar su verdadera condición jurídica. La relación de trabajo ambigua es cuando se realiza un trabajo o se prestan servicios en circunstancias que suscitan una duda genuina y razonable sobre si existe o no una relación de trabajo. Sobre las relaciones de trabajo encubiertas o ambiguas. El ámbito de la relación de trabajo, Informe V, Conferencia Internacional del Trabajo, 91. ${ }^{a}$ reunión, Oficina Internacional del Trabajo, Ginebra, 2003, págs. 21-42.

16 A este respecto, la Conferencia puntualiza que este fenómeno de incumplimiento de la ley se ha difundido mucho en los países en desarrollo, aunque también se observa en países industrializados. Los medios para hacer ejecutar las leyes del trabajo no se usan como es debido. El ámbito de la relación de trabajo, Informe V, Conferencia Internacional del Trabajo, 91. ${ }^{a}$ reunión, Oficina Internacional del Trabajo, Ginebra, 2003, pág. 38. 
especial, la administración y la inspección del trabajo y los propios tribunales de justicia ${ }^{17}$.

Una vez más, la Conferencia estudia en esta reunión las relaciones de trabajo triangulares, en aumento en los últimos años. Estas relaciones, en las que los trabajadores se hallan ante varios interlocutores, pueden ser beneficiosas para todos los interesados, pero en ciertas circunstancias también pueden ser fuente de desprotección. En estos casos, resulta indispensable determinar quién es el empleador, cuales son los derechos del trabajador y quién responde por los mismos. Las relaciones de trabajo triangulares pueden comprender además, situaciones de encubrimiento o de ambigüedad ${ }^{18}$.

En cuanto a la dimensión de género, se advierte de los siguientes hechos:

- Las desigualdades de protección que se crean cuando hablamos de las trabajadoras.

- En la economía informal es dónde más se produce la desprotección y son las mujeres las que más participan en ella.

- En consecuencia, la falta de protección laboral de los trabajadores dependientes agrava las desigualdades de género que se producen en el trabajo ${ }^{19}$.

Es cierto que los datos de todo el mundo nos revelan que la participación de las mujeres en la fuerza de trabajo ha aumentado, pero también nos muestran que este incremento se da principalmente en la economía informal, que es dónde se concentran la mayoría de relaciones de trabajo ambiguas o encubiertas. La dimensión de género del problema, se ve entonces reforzada por el hecho del predominio de las mujeres en sectores y ocupaciones dónde las relaciones de trabajo de este tipo son frecuentes, como en el trabajo doméstico y a

${ }_{17}$ El aumento de las competencias de la Administración de trabajo en materia socio-laboral, de empleo, prevención de riesgos y protección social, y el protagonismo que reconocen los estados miembros a la Inspección del trabajo como garante del cumplimiento de la legislación laboral y de la protección de los trabajadores lo indican CASAle, G. y Monereo Pérez, J. L., A treinta años de la adopción del Convenio n. ${ }^{\circ} 150$ de la OIT sobre la Administración del Trabajo. Un diálogo entre Europa y América Latina, Editorial Comares, Granada, 2010, págs. 151 -154.

18 Sobre las relaciones de trabajo triangulares. El ámbito de la relación de trabajo, Informe V, Conferencia Internacional del Trabajo, 91. a reunión, Oficina Internacional del Trabajo, Ginebra, 2003, págs. 43-59.

19 Resolución relativa a la relación de trabajo, Conferencia General de la Organización Internacional del Trabajo, Ginebra, 2003, punto 15. 
domicilio, los puestos de trabajo en la industria textil, confección, ventas o supermercados, enfermería o servicios de asistencia ${ }^{20}$.

El informe también advierte que la exclusión o restricciones de los derechos que se practican, afectan en mayor medida a las mujeres que a los hombres y que incluso en la desprotección existe una notable desigualdad entre trabajadoras y trabajadores ${ }^{21}$.

Como medidas específicas que deberían tomar los países para abordar con eficacia la dimensión de género en la falta de protección en las relaciones de trabajo, la Conferencia apuntó las siguientes ${ }^{22}$ :

— La adopción de políticas más claras en relación con la igualdad de género.

- Una mejor aplicación de las leyes pertinentes en el plano nacional. Las administraciones de trabajo y sus servicios, en colaboración con los interlocutores sociales, deberían realizar controles sistemáticos de los programas y procedimientos de aplicación y divulgación de la ley. Se deberían determinar los sectores y grupos profesionales con niveles elevados de trabajo encubierto y adoptar planes estratégicos de cumplimiento de la normativa, así como prestar especial atención a los sectores y ocupaciones con proporción elevada de trabajadoras.

- A nivel internacional, la ratificación del Convenio núm. 100, sobre la igualdad de remuneración, el Convenio núm. 111, sobre la discriminación (empleo y ocupación), y el Convenio núm. 183, sobre la protección de la maternidad, de aplicación a todas las mujeres empleadas, incluidas las que desempeñan formas atípicas de trabajo dependiente.

${ }^{20}$ Fundamentalmente, los efectos o consecuencias prácticas de la discriminación social de la mujer se traducen en una segregación ocupacional del mercado de trabajo, tanto vertical con el llamado «techo de cristal», como horizontal con la existencia de sectores «feminizados» y la mayor presencia de mujeres en empleos precarios, como explica FaBRegat Monfort, G., La discriminación de género en el acceso al mercado de trabajo. La posibilidad de una nueva tutela a la luz de la Ley Orgánica 3/2007, de 22 de marzo, para la igualdad efectiva de mujeres y hombres, Tirant lo Blanch, Valencia, 2008, pág. 54 y Las medidas de acción positiva. La posibilidad de una nueva tutela antidriscriminatoria, Tirant lo Blanch, Valencia, 2009, págs. 15-16.

${ }_{21}$ El ámbito de la relación de trabajo, Informe V, Conferencia Internacional del Trabajo, 91. . reunión, Oficina Internacional del Trabajo, Ginebra, 2003, págs. 10-11.

22 Resolución relativa a la relación de trabajo, Conferencia General de la Organización Internacional de Trabajo, Ginebra, 2003, puntos 16 y ss. 
- A nivel nacional y sectorial y de forma periódica, la recopilación de datos estadísticos y la investigación y realización de estudios sobre los cambios de estructuras y modalidades de trabajo. Todos los datos recopilados deberían clasificarse por sexo y las investigaciones y los estudios realizados incluir explícitamente la dimensión de género.

La OIT reconoce que tiene una importante función que desempeñar en esta materia y que debe centrar sus esfuerzos en la cooperación técnica, la asistencia y la orientación, el diálogo con otras instituciones internacionales, la recopilación de datos y la elaboración y publicación de estudios comparativos que tengan en cuenta la dimensión relativa al género y la promoción de prácticas adecuadas.

Como respuesta internacional, se propone la adopción de una recomendación que pueda orientar a los Estados y que, al mismo tiempo, sea lo suficientemente flexible como para tener en cuenta las diferentes tradiciones económicas, sociales, jurídicas y de relaciones laborales. Una recomendación que contemple las relaciones de trabajo encubiertas, la promoción del diálogo social, los mecanismos que garantizan la protección de todos los trabajadores, sin olvidar los grupos más vulnerables, y que afronte los problemas de género.

En el año 2006, la Oficina Internacional del Trabajo elabora un nuevo informe en el que se aborda de forma exhaustiva la relación de trabajo, tanto en la legislación como a nivel práctico ${ }^{23}$. El estudio abarca un amplio abanico de normas y prácticas en vigor en más de 60 Estados miembros de la OIT de diversas regiones y diferentes tradiciones y ordenamientos jurídicos.

Dicho informe, irá acompañado de un cuestionario enfocado a la adopción de la recomendación, siempre de acuerdo con la orientación de la discusión general de 2003.

Se insiste en la importancia de la acción a nivel nacional, que deberá incluir el desarrollo de una política elaborada en consulta con los interlocutores sociales, la recolección de datos estadísticos, actuaciones claras en materia de igualdad de género y una mayor vigilancia del cumplimiento y aplicación de la ley ${ }^{24}$.

${ }^{23}$ La relación de trabajo, Informe V (1), Conferencia Internacional del Trabajo, 95. ${ }^{\text {a }}$ reunión, Oficina Internacional del Trabajo, Ginebra, 2006.

${ }^{24}$ La relación de trabajo, Informe V (1), Conferencia Internacional del Trabajo, 95. a reunión, Oficina Internacional del Trabajo, Ginebra, 2006, Capítulo III. Un nuevo instrumento: bases y posible contenido de una recomendación, pág. 55. 
Por fin este año, la Conferencia General adopta la Recomendación núm. 198, sobre la relación de trabajo ${ }^{25}$.

Desde un primer momento, la Conferencia entendió que una recomendación sería el instrumento internacional correcto y consideró suficiente la orientación a los Estados en la aplicación de políticas y en la adopción de normas que regulasen un nivel adecuado de protección para todos los trabajadores y las garantías necesarias para su cumplimiento ${ }^{26}$.

La finalidad primera de la Recomendación sería concienciar de la importancia de la protección de los todos los trabajadores sujetos a una relación laboral y de las repercusiones sociales que pueda tener esa ausencia de protección incluso a nivel nacional.

La Recomendación no dará unas pautas precisas de las políticas a seguir en la relación de trabajo y será a cada Estado a quien corresponda, según sus características y circunstancias, aplicar las que más convengan para identificar a los trabajadores que carecen de protección y establecer las medidas más adecuadas para su solución. Sin embargo, sí propondrá elementos que podrían formar parte de esas políticas nacionales y los criterios para la determinación de la existencia de una relación de trabajo. En todo caso, las políticas nacionales deberán encaminarse siempre a garantizar que los trabajadores que realmente estén vinculados por una relación de trabajo reciban una adecuada protección de la ley, ser transparentes y estar formuladas sobre una base tripartita. En los países donde ya se estén aplicando las políticas propuestas en la Recomendación, los esfuerzos deberán dirigirse a su evaluación y seguimiento con regularidad $^{27}$.

${ }^{25}$ Recomendación núm. 198, sobre la relación de trabajo, adoptada el 15 de junio de 2006.

${ }^{26}$ Como explica ERmida URIARTE, O., aunque las recomendaciones sean orientaciones no plenamente vinculantes, a diferencia de los convenios internacionales del trabajo que una vez ratificados se incorporan al ordenamiento jurídico nacional siendo plenamente exigibles, producen efectos que bien explotados pueden ser de gran utilidad para el Derecho laboral y los trabajadores. Por una parte, suponen un control para los gobiernos al tener que informar periódicamente a la OIT en la materia regulada en el país. Además, son orientaciones para el legislador y el ejecutivo nacional y, sobre todo, para los jueces a la hora de solucionar casos concretos que «pueden aplicar la recomendación (así como cualquier otra), tanto en la integración del derecho (en caso de vacío legal) como en la interpretación de las normas vigentes». La Recomendación 198 sobre la relación de trabajo y su importancia para los trabajadores, GTAS, III, Reunión, Lima, 2010, págs. 5-6.

${ }^{27}$ La relación de trabajo, Informe V (1), Conferencia Internacional del Trabajo, 95. ${ }^{a}$ reunión. 2006. Oficina Internacional del Trabajo, Ginebra, Capítulo III: Un nuevo 
La parte I de la Recomendación señala como contenido mínimo de la política nacional, la determinación eficaz de la existencia de la relación de trabajo, la lucha contra las relaciones de trabajo encubiertas, la regulación de los derechos de los trabajadores asalariados y de la responsabilidad de la protección, al acceso a procedimientos de solución de controversias eficaces, el cumplimiento y la aplicación efectiva de la legislación y la formación jurídica apropiada de los árbitros, mediadores e inspectores de trabajo ${ }^{28}$.

La preocupación en el debate por el aumento de las formas atípicas de empleo y de la subcontratación de los trabajadores más vulnerables y por las desigualdades de protección que sufren las trabajadoras, quedan reflejadas en varias referencias específicas a la igualdad de género y a la no discriminación. El párrafo 5 precisa que «los Miembros deberían velar en particular por asegurar una protección efectiva a los trabajadores especialmente afectados por la incertidumbre en cuanto a la existencia de una relación de trabajo, incluyendo a las trabajadoras, así como a los trabajadores más vulnerables, los jóvenes trabajadores, los trabajadores de edad, los trabajadores de la economía informal, los trabajadores migrantes y los trabajadores con discapacidades» y en el párrafo 6 insta a los países a «velar especialmente por que en la política nacional se aborde la cuestión de la dimensión de género, dado que las mujeres que trabajan predominan en determinados sectores y ocupaciones en los que existe una elevada proporción de relaciones de trabajo encubiertas o en los que existe falta de claridad en lo que atañe a la relación de trabajo» y a «establecer políticas claras sobre la igualdad de género y mejorar el cumplimiento de la legislación y los acuerdos pertinentes en el ámbito nacional, de modo que pueda abordarse de manera eficaz la dimensión de género».

instrumento: bases y posible contenido de una recomendación, Sección III: Contenido del instrumento, págs. 56 a 58.

Sobre la flexibilidad de las normas de la OIT escribe BonEt PÉREz, J., «Si la flexibilidad de las normas jurídicas adoptadas en el seno de la OIT facilita, en teoría, su aplicación universal, no es menos cierto que representa un relativo fraccionamiento del régimen jurídico establecido en los Convenios de la OIT; es por ello que en la acción normativa de la OIT es un factor determinante la búsqueda del equilibrio entre la universalidad del estándar jurídico internacional y la especificidad de las situaciones particulares de los Estados». Bonet PéREz, J., Mundialización y régimen jurídico internacional del trabajo. La Organización Internacional del Trabajo como referente político-jurídico universal, Atelier Internacional, Barcelona, 2007, pág. 103 .

${ }_{28}$ Recomendación núm. 198, sobre la relación de trabajo, adoptada el 15 de junio de 2006, párrafo 4. 
La parte II de la Recomendación se centra en la manera de determinar la existencia de la relación de trabajo y en la solución de controversias y el cumplimiento de la ley, dos de los puntos principales de las discusiones.

En cuanto a la determinación de la relación de trabajo, la Recomendación de la OIT supera el criterio tradicional de la subordinación jurídica como elemento definitorio y basa la determinación de la relación de trabajo en el principio de la realidad, de mayor amplitud $^{29}$.

Para su definición, sugiere la admisión de una amplia variedad de medios y promueve la presunción legal de su existencia cuando se den uno o varios de los indicios que enumera, tales como la existencia de instrucciones y control, la integración en la organización de la empresa, la realización del trabajo en beneficio ajeno, la ejecución personal del trabajo, la realización de trabajo en un lugar y horario determinado, la disponibilidad del trabajador, el suministro de medios para realizar el trabajo, la periodicidad de la remuneración, el pago en especie, o el reconocimiento de derechos típicamente laborales como el descanso semanal o las vacaciones ${ }^{30}$.

La existencia de una relación de trabajo podría determinarse entonces en función de los hechos relativos a la ejecución del trabajo, independientemente de la calificación jurídica que las partes hagan de la relación que las vincula o del criterio único de la subordinación o dependencia.

En lo concerniente a la correcta aplicación y vigilancia de la ley, que afecta a la relación de trabajo y por ende a la protección de los derechos del trabajador, la OIT reclama una mayor voluntad por parte de los Estados.

Las políticas nacionales deberían asegurar el acceso efectivo de los trabajadores y los empleadores a los tribunales o instancias de arbitraje para la solución de controversias sobre la existencia y las

29 «La determinación de la existencia de una relación de trabajo debe ser guiada por los hechos de los que realmente fue convenido y llevado a cabo por las partes, y no por la manera como una de las partes o las dos partes describen la relación de trabajo. Esto es lo que se conoce en derecho como el principio de la primacía de la realidad. En general, el juez debe decidir en base a los hechos». La relación de trabajo. Informe V (1) Oficina Internacional del Trabajo, Ginebra, 2006, Capítulo II: Tendencias y Problemas en la regulación: análisis comparativo. Determinación de la existencia de la relación de trabajo, pág. 24.

${ }^{30}$ Recomendación núm. 198, sobre la relación de trabajo, adoptada el 15 de junio de 2006, párrafos 9 a 13 . 
condiciones de la relación de trabajo, la adopción de medidas eficaces para garantizar la observancia y la aplicación de la legislación a través de los servicios de inspección de trabajo, seguridad social y autoridades fiscales y la eliminación de los incentivos que fomentan las relaciones de trabajo encubiertas. Se recomienda además, la supervisión periódica por parte de las administraciones de sus programas y dispositivos de control del cumplimiento, con especial atención a las ocupaciones y sectores con proporción elevada de mujeres trabajadoras y la negociación colectiva y el diálogo social como medios para encontrar soluciones a las cuestiones relativas a la relación de trabajo ${ }^{31}$.

La Parte III y última de la Recomendación, hace referencia al seguimiento de la evolución del mercado y de la organización del trabajo y a la aplicación de medidas relativas a la relación de trabajo en el marco de la política nacional. Advierte de la importancia de la participación de las organizaciones de empleadores y trabajadores, la recopilación de información y de datos estadísticos, la realización de estudios sobre los cambios registrados en la estructura y las modalidades de trabajo a nivel nacional y sectorial teniendo en cuenta la distribución entre hombres y mujeres, así como el establecimiento de mecanismos nacionales específicos para asegurar la determinación de la existencia de relaciones de trabajo en el marco de la prestación de servicios transnacionales ${ }^{32}$.

31 Recomendación núm. 198, sobre la relación de trabajo, adoptada el 15 de junio de 2006, párrafos 14 a 18 .

32 Recomendación núm. 198, sobre la relación de trabajo, adoptada el 15 de junio de 2006, párrafos 19 a 22.

Con la Recomendación núm. 198, la Conferencia General adopta una resolución sobre la relación de trabajo, en la que invita a la Oficina Internacional del Trabajo a prestar asistencia a los mandantes en lo que atañe a los de mecanismos de aplicación y seguimiento de la política nacional a la que se refiere la Recomendación y a mantener información actualizada y emprender estudios comparativos sobre la evolución de los modelos y las estructuras laborales en el mundo. Resolución relativa a la relación de trabajo, Conferencia General de la Organización Internacional del Trabajo, 95. ${ }^{\circ}$ reunión, Ginebra, 2006, puntos 1 y 2. El Servicio de Diálogo Social, Legislación y Administración del Trabajo de la OIT publica además, una guía anotada que contiene información práctica sobre la manera en que los países están abordando diversas cuestiones de la relación de trabajo de conformidad con lo estipulado en la Recomendación núm. 198. La Relación de trabajo. Una guía anotada a la Recomendación N. 198, Oficina Internacional del Trabajo, Servicio de Diálogo Social, Legislación y Administración del Trabajo, Ginebra, 2008. Así, por ejemplo, contempla las medidas adoptadas por algunos países como Canadá o Países Bajos para la protección de los grupos más vulnerables que postula el párrafo 5. Págs. 22-23. 


\section{LA PROTECCIÓN DE LOS TRABAJADORES Y EL PROGRAMA DEL TRABAJO DECENTE}

Con la Declaración sobre la justicia social para una globalización equitativa de 2008, la Organización reconoce una vez más la trascendencia de la relación de trabajo como medio para ofrecer protección jurídica a los trabajadores. La Conferencia pone de nuevo sobre la mesa los profundos cambios y consecuencias producidos en el mundo del trabajo debido a la integración económica mundial, como la creación de empleo en algunos países, y el desempleo y el aumento del trabajo no protegido y de la economía informal en otros, cambios que influyen en la relación de trabajo y la protección que ésta puede ofrecer ${ }^{33}$.

La Declaración institucionaliza el concepto de trabajo decente desarrollado por la OIT desde 1999. La puesta en práctica del Programa del Trabajo Decente se logra a través de la aplicación de políticas económicas y sociales basadas en sus cuatro objetivos estratégicos: la creación de empleo, la garantía de los derechos de los trabajadores, la extensión de la protección social y la promoción del diálogo social. Objetivos «inseparables, interrelacionados y que se refuerzan mutuamente» y que tienen como objetivo transversal la igualdad de género y la no discriminación ${ }^{34}$.

La Declaración proclama el compromiso de los Miembros y de la Organización para adoptar y ampliar en el marco del Programa del Trabajo Decente medidas de protección social - seguridad social y protección de los trabajadores-, que sean sostenibles y estén adaptadas a las circunstancias nacionales, con inclusión de la ampliación de la seguridad social, condiciones de trabajo saludables y seguras, y medidas en materia de salarios ${ }^{35}$.

${ }^{33}$ Declaración de la OIT sobre la justicia social para una globalización equitativa, adoptada el 10 de junio de 2008.

${ }^{34}$ El concepto de trabajo decente se basa en el reconocimiento de que el trabajo es fuente de dignidad personal y de respeto, estabilidad familiar, desarrollo de las empresas, crecimiento económico y progreso social. El derecho al trabajo decente, o mejor al trabajo digno, es el derecho a condiciones de trabajo equitativas, satisfactorias, dignas y justas. El derecho a un trabajo decente como derecho social fundamental y la precariedad laboral como su antónimo lo explican Monereo Pérez, J. L., y LóPEz UnSUA, B. M., «La garantía internacional del derecho a un «trabajo decente», Revista Española del Derecho del Trabajo, núm. 177, 2015, págs. 6 y ss.

${ }^{35}$ Declaración de la OIT sobre la justicia social para una globalización equitativa, adoptada el 10 de junio de 2008, punto I. Alcance y Principios ii. 
Bajo el lema "promover el trabajo y proteger a las personas», y ante la situación de crisis y el incremento mundial del desempleo, el 19 de junio de 2009 se adopta unánimemente en la 98. a reunión de la Conferencia Internacional del Trabajo, el Pacto Mundial para el Empleo.

Guiado por el Programa de Trabajo Decente y la Declaración de la OIT de 2008, el Pacto recomienda para la recuperación y el desarrollo, la puesta en marcha de políticas encaminadas a la inversión y a la creación de empleo sostenible, la ampliación de la protección social, el respeto de las normas laborales contenidas en los Convenios y Recomendaciones de la OIT y los principios y derechos fundamentales en el trabajo, la promoción del el diálogo social y el fomento de una globalización equitativa. Con el apoyo y asesoramiento prestados por la Organización, se alienta a los mandantes a que apliquen los elementos del Pacto que mejor respondan a las necesidades y prioridades de su país ${ }^{36}$.

La Conferencia de las Naciones Unidas sobre el Desarrollo Sostenible celebrada en Río de Janeiro en junio de 2012, acuerda en su documento final establecer un Grupo de Trabajo Abierto que tendrá como obligación elaborar un conjunto de objetivos de desarrollo sostenible a alcanzar a partir del año $2015^{37}$.

Tras un proceso de negociaciones intergubernamentales, y tomando como base la propuesta contenida en el Informe del Grupo de Trabajo Abierto, la Asamblea General aprueba en septiembre de 2015 la Agenda para el desarrollo posterior a 2015, en el documento «Transformar nuestro mundo: La Agenda 2030 para el Desarrollo Sostenible», en vigor desde el 1 de enero de 2016 y válida para los próximos quince años ${ }^{38}$.

La nueva Agenda se basa en los objetivos que se fijaron en la Declaración del Milenio, y aspira a conseguir los que estos no lograron: 17 objetivos y 169 metas de carácter integrado e indivisible, interrela-

${ }^{36}$ Como explica GIL y GIL, J. L., es el programa de trabajo decente aplicado al contexto de la crisis. El pacto reafirma la importancia del trabajo decente y pone el empleo y la protección social en el centro de las respuestas a la crisis. GIL y GIL, J. L., Globalización y empleo: «Propuestas de la OIT para un desarrollo sostenible», Revista Doctrinal Aranzadi Social, núm. 11, 2014, págs. 10-11.

37 Río de Janeiro, Brasil del 20 al 22 de junio de 2012, conocida como Conferencia Rio+20. Documento final. El futuro que queremos. A/RES/66/288, anexo, aprobada por la Asamblea General de Naciones Unidas el 27 de julio de 2012.

${ }^{38}$ Transformar nuestro mundo: La Agenda 2030 para el Desarrollo Sostenible. Resolución A/70/L.1, aprobada por la Asamblea General de Naciones Unidas el 25 de septiembre de 2015. 
cionados y vinculados, que conjugan las tres dimensiones del desarrollo sostenible: económica, social y ambiental.

El Objetivo de Desarrollo Sostenible 8 de la nueva Agenda de Naciones Unidas, fija como propósito a alcanzar por los países miembros antes de 2030 la promoción del crecimiento económico sostenido, inclusivo y sostenible, el empleo pleno y productivo, y el trabajo decente para todos los hombres y mujeres, incluidos los jóvenes y las personas con discapacidad y la igualdad de remuneración por trabajo de igual valor (meta 8.5). También establece como meta la protección de los derechos laborales y la promoción de un entorno de trabajo seguro y protegido para todos los trabajadores, incluidos los trabajadores migrantes, en particular las mujeres migrantes y las personas con empleos precarios (meta 8.8). Además muchos aspectos del trabajo decente están presentes en los demás objetivos y metas de la Agenda $2030^{39}$.

La igualdad y la no discriminación entre los géneros y el empoderamiento de todas las mujeres y niñas ha sido siempre un reto fundamental para las Naciones Unidas, y por eso se incluye en la Agenda 2030 como objetivo independiente y también de forma transversal en los demás. El Objetivo de Desarrollo Sostenible 5 fija como objetivo específico la igualdad entre los géneros y el empoderamiento de las mujeres y entre sus metas están las de poner fin a todas las formas de discriminación contra las mujeres y niñas de todo el mundo (meta 5.1), reconocer y valorar los cuidados y el trabajo doméstico no remunerado mediante la prestación de servicios públicos, la provisión de infraestructuras y la formulación de políticas de protección social, así como mediante la promoción de la responsabilidad compartida en el hogar y la familia (meta 5.4), asegurar la igualdad de oportunidades de liderazgo de la mujer a todos los niveles y su participación plena y efectiva en la adopción de decisiones en la vida política, económica y pública (meta 5.5), o aprobar leyes y políticas para promover la igualdad entre los géneros y el empoderamiento de las mujeres y niñas a todos los niveles (meta 5.c).

También en el año 2015, la Conferencia celebra una discusión recurrente sobre la protección social de los trabajadores, de conformidad con la Declaración de la OIT sobre la justicia social para una globalización, en la que se definen las prioridades de actuación de la Organización para lograr una protección de los trabajadores más in-

${ }^{39}$ La importancia del trabajo decente para realizar el desarrollo sostenible se pone de manifiesto en El trabajo decente y la Agenda 2030 de Desarrollo Sostenible, Organización Internacional del Trabajo, Ginebra, 2016. 
cluyente y efectiva. En el mismo periodo de sesiones, la Conferencia aprueba además la Recomendación sobre la transición de la economía informal a la economía formal ${ }^{40}$.

En las discusiones, los representantes de los trabajadores pusieron de manifiesto que uno de los principales obstáculos para hacer efectiva la protección de los trabajadores era la falta de universalidad. Si las normas del trabajo no se aplican a todas las personas sería cada vez más difícil aplicarlas incluso a un grupo de ellas. Sin embargo, los expertos empleadores afirmaban que la protección universal de los trabajadores es un concepto ambiguo y no tiene en cuenta la diversidad de los contextos nacionales, las diferentes necesidades de los trabajadores y los recursos disponibles en cada país para la cobertura de la protección. Se debe fomentar un entorno que promueva la transición de la economía informal a la economía formal, y unas normas demasiado rígidas pueden hacer más difícil su cumplimiento. En la discusión se citó como ejemplo a seguir el Programa de Adecuación y Eficacia de la Regulación de la Comisión Europea de la Unión Europea ${ }^{41}$.

Los expertos empleadores expresaron también su malestar por la negatividad de los anteriores informes de la OIT, y señalaron que los cambios en el mundo del trabajo deberían considerarse desde una perspectiva más positiva. Se olvidaba la falta de capacidad de las empresas para ofrecer trabajo a tiempo completo y pagar a sus trabajadores, especialmente en las PYMES. Las formas atípicas de empleo, si estaban bien diseñadas y reguladas, podrían proteger a los trabajadores y al mismo tiempo ayudar a las empresas a adaptarse a las demandas del mercado. Varias reuniones tripartitas de expertos habían puesto de manifiesto los aspectos positivos de las modalidades de trabajo flexible, que constituían una herramienta importante para evitar la pérdida de puestos de trabajo y sustentar a las empresas en tiempos de crisis. El trabajo flexible puede facilitar el equili-

${ }^{40}$ Recomendación sobre la transición de la economía informal a la economía formal, núm. 204, adoptada el 12 de junio de 2015.

${ }^{41}$ El Programa de Adecuación y Eficacia de la Regulación de la Comisión Europea (REFIT), contempla medidas para simplificar la normativa de la Unión Europea y reducir los costes que ocasiona, contribuyendo así a un marco reglamentario claro, estable, previsible y propicio al crecimiento y el empleo. El 19 de mayo de 2015, la Comisión Europea decidió crear una plataforma REFIT para asesorarse sobre cómo simplificar la legislación de la Unión Europea y hacerla más eficaz. El 13 de abril de 2016, el Parlamento Europeo, el Consejo de la Unión Europea y la Comisión Europea, firmaron el Acuerdo Interinstitucional «Legislar mejor», que aportará cambios en todo el ciclo de formulación de políticas, desde las consultas y la valoración de impacto hasta la adopción, la aplicación y la evaluación del Derecho de la Unión Europea. 
brio entra la vida profesional y personal. Estas modalidades de trabajo no van a desaparecer y sería necesario que la OIT estudiara la forma de extender la protección de los trabajadores a las nuevas formas de contratos de trabajo, sin desincentivar la contratación por parte de las empresas y promoviendo las formas de empleo flexibles debidamente reguladas ${ }^{42}$.

Los participantes mostraron gran preocupación por la percepción que existe a nivel global de que la protección de los trabajadores representa un coste en las sociedades y en las economías, cuando en realidad debería entenderse como una inversión, además de equiparar las condiciones de la competencia. Los empleadores explicaron que la responsabilidad de la protección de los trabajadores, no debería recaer enteramente en ellos y que los costes que conllevan la aplicación de las medidas de protección apropiadas deberían distribuirse de forma más adecuada o racional. Argumentaron que los accidentes de trabajo no están necesariamente vinculados a la situación contractual y que si bien era imposible determinar de forma concluyente si los riesgos psicosociales en el trabajo eran cada vez más habituales, no cabía duda de que el desempleo sí tenía efectos psicosociales negativos. La regulación de medidas bien intencionadas en materia de seguridad y salud podría tener como contrapartida un aumento del desempleo y del trabajo informal. También el Convenio núm. 193, sobre la protección de la maternidad, puede propiciar prácticas de contratación discriminatorias contra las mujeres si la totalidad de los gastos asociados a ellas recaen en los empleadores. Las mujeres no deberían resultar perjudicadas ni en el acceso y ni en las oportunidades en el empleo debido al aumento de coste que supone para los empleadores, y sería importante analizar la discriminación en la contratación de mujeres debido a la protección de la maternidad ${ }^{43}$.

Los empleadores también observaron que sería necesario evaluar la repercusión de las medidas de protección de los trabajadores en las PYMES y la sostenibilidad de estas empresas. La OIT debería adoptar una perspectiva de análisis más amplia. Sin duda, a las PYMES les interesa garantizar entornos de trabajo seguros y saluda-

${ }^{42}$ Reunión tripartita de expertos sobre la ordenación del tiempo de trabajo, Conferencia Internacional del Trabajo. Informe final, Oficina Internacional del Trabajo, Ginebra, 2011. Conclusiones de la Reunión de expertos sobre las formas atípicas de empleo, Consejo de Administración, Oficina Internacional del Trabajo, 323. . reunión, Ginebra, 2015.

${ }_{43}$ Convenio núm. 183, relativo a la revisión del Convenio sobre la protección de la maternidad (revisado), adoptado el 15 de junio de 2000. 
bles para mantener su competitividad, pero para ello habría que establecer los apoyos y marcos necesarios sin añadir cargas adicionales e innecesarias ${ }^{44}$. En relación a la igualdad de género se explicó que si los cuatro ámbitos de política de los trabajadores se abordaran eficazmente en todos los países, probablemente habría una reducción de la desigualdad de género. Estados Unidos y Canadá proponen tratar la cuestión de la protección de las trabajadoras como cuestión prioritaria.

Se recuerda que la OIT tiene una labor muy importante de promoción de medidas que eviten la disparidad salarial entre hombre y mujeres y las deficiencias en la cobertura de la protección de la maternidad, así como del fomento de políticas que mejoren las condiciones de seguridad y salud en el trabajo, y el equilibrio entre la vida laboral y la vida privada de los trabajadores. También en el asesoramiento y apoyo directo a los gobiernos y a las organizaciones de empleadores y trabajadores, y en la recopilación y análisis de datos.

Durante la discusión, se propuso realizar un estudio de la relación existente entre la protección de los trabajadores y la productividad de las empresas.

La aprobación de nuevos instrumentos normativos internacionales que regulasen la relación de trabajo y la protección de los trabajadores fue otro de los puntos a tratar. Los cambios en el mundo del trabajo habían aumentado la flexibilidad en la contratación pero al mismo tiempo incrementado el número de trabajadores cuya situación laboral no estaba clara o que no gozaban de las protecciones asociadas normalmente con la relación de trabajo y resultaba indispensable la adaptación de la legislación laboral a las nuevas circunstancias ${ }^{45}$. Sin embargo, la escasa ratificación de las normas adoptadas por la OIT demostraba que la ampliación de la regulación no iba

${ }^{44}$ La OIT ya advertía en su Informe de 2009 sobre la igualdad de género que «Desde hace tiempo, las organizaciones de empleadores han venido reclamando que se reconozcan los problemas a que se ven confrontadas las empresas, en particular las PYMES, cuando deben asumir solas la responsabilidad de la protección de la maternidad. Los empleadores esperan con justa razón, no tener que sufragar aquellos costos financieros y de cumplimiento que no les correspondan derivados de la licencia de maternidad y han insistido en que los gobiernos deberían adoptar políticas nacionales que se ajusten a las expectativas económicas y sociales de la comunidad en general». La igualdad de género como eje del trabajo decente, Informe VI, Conferencia Internacional del Trabajo, $98 .^{\circ}$ reunión, Oficina Internacional del Trabajo, Ginebra, 2009, punto 119, pág. 63 .

45 "The employment relationship. A comparative overview. La relación de trabajo: una visión global comparativa, Resumen ejecutivo, Oficina Internacional del Trabajo, Ginebra, 2011, pág. 4. 
a implicar necesariamente la extensión de la protección. Sería más acertada la revisión, actualización y promoción de las normas ya existentes, y se insistió como siempre en la observancia de la ley dentro de cada país y en el valor de la inspección de trabajo.

Entre las conclusiones de la discusión de la Conferencia están las siguientes ${ }^{46}$ :

1. La protección de los trabajadores y la seguridad social son complementarias y proporcionan la protección social que requieren los trabajadores y sus familias.

2. La protección efectiva e incluyente de los trabajadores se logra a través de la reglamentación de las condiciones de trabajo en los ámbitos de los salarios, el tiempo de trabajo, la seguridad y salud en el trabajo (SST) y la protección de la maternidad. El fortalecimiento de la protección en uno de los ámbitos tiene implicaciones positivas en los demás. Se debería reforzar la dimensión de género en los cuatro ámbitos de la protección de los trabajadores.

3. Para una aplicación efectiva de la reglamentación se debería tener en cuenta la diversidad del mercado. Para las pequeñas y medianas empresas (PYMES) la aplicación efectiva de la protección supone un gran esfuerzo.

4. Se debería facilitar la transición de la informalidad a la formalidad. El beneficio sería global. En el caso de los trabajadores, la formalidad permite que más trabajadores se beneficien de un nivel adecuado de protección. En el caso de las empresas, les permite acceder al crédito y les proporciona protección jurídica, iguala las condiciones y reduce la competencia desleal. En el caso de los gobiernos y de la sociedad en general, la formalización ayuda a aumentar la base impositiva y, por tanto, financiar los programas de protección social, los servicios públicos de empleo y la inspección del trabajo.

${ }^{46}$ Discusión recurrente sobre el objetivo estratégico de la protección social (protección de los trabajadores) con arreglo al seguimiento de la Declaración de la OIT sobre la justicia social para una globalización equitativa, de 2008 y Conclusiones relativas a la discusión recurrente sobre la protección social (protección a los trabajadores), Conferencia Internacional del Trabajo, 104. ${ }^{a}$ reunión, Ginebra, 2015, págs. 1-8. y Resumen de las deliberaciones, págs. 10-11. 
5. Se debería garantizar el cumplimiento de la normativa, la creación de sistemas de administración e inspección de trabajo eficaces y el diálogo social.

La OIT reconoce la necesidad de realizar un mejor seguimiento y comprensión de los cambios en el mundo del trabajo y que es indispensable adaptar las leyes laborales a las nuevas realidades si no queremos que resulten ineficaces. También se debería revisar el enfoque adoptado en lo concerniente a la protección de los trabajadores, para garantizar una distribución más equilibrada de los riesgos entre los empleadores, los trabajadores y el Estado ${ }^{47}$.

Las prioridades de la actuación de la OIT para lograr una protección de los trabajadores más incluyente y efectiva, quedaron definidas en la misma reunión como sigue:

1. Tomar como medidas preferentes:

a. La ratificación y aplicación efectiva de los convenios fundamentales y las normas internacionales del trabajo sobre protección de los trabajadores.

b. El análisis de posibles lagunas en las normas e instrumentos internacionales que no responden de manera suficiente a la realidad actual del mundo del trabajo.

c. La asistencia a los mandantes de la OIT para que puedan poner en práctica la normativa internacional del trabajo teniendo en cuenta las circunstancias nacionales particulares.

d. Mejorar la labor de recopilación de datos, incluida la Clasificación Internacional de la Situación de Empleo (ICSE$93)^{48}$, de modo que refleje la naturaleza cambiante de la

47 Discusión recurrente sobre el objetivo estratégico de la protección social (protección de los trabajadores) con arreglo al seguimiento de la Declaración de la OIT sobre la justicia social para una globalización equitativa, de 2008. Resumen de las deliberaciones, Conferencia Internacional del Trabajo, 104. ${ }^{a}$ reunión, Ginebra, 2015, págs. 10-11.

${ }^{48} \mathrm{La}$ Clasificación Internacional de la Situación de Empleo (CISE-93), fue adoptada a través de una resolución de la Decimoquinta Conferencia Internacional de Estadísticos del Trabajo (CIET), en enero de 1993. Es la norma internacional actual para las estadísticas sobre la relación de empleo y tiene dos funciones: aportar un modelo para el desarrollo de clasificaciones nacionales de estadísticas sobre la situación en el empleo y sentar las bases para la producción de estadísticas comparables internacionalmente sobre el tema. La CISE-93 clasifica los empleos de una persona en un momento en el tiempo. Se compone de los siguientes grupos: 1 . Empleados (los países pueden hacer una distinción suplementaria creando un gru- 
relación de trabajo; desarrollar las publicaciones relacionadas con la protección de los trabajadores, entre ellos el Informe mundial de salarios, y realizar estudios sobre los puntos de vista innovadores e incluyentes de la negociación colectiva.

e. Aumentar la cooperación técnica y asesoramiento en las políticas nacionales, y crear instituciones que aborden la protección de trabajadores de manera incluyente y que tenga en cuenta la dimensión de género y la ampliación de la protección a los grupos excluidos ${ }^{49}$.

f. Mayor sensibilización en la necesidad de la protección de todos los trabajadores y del respeto a los derechos y obligaciones en el trabajo.

g. Evaluar los progresos conseguidos en los cuatro ámbitos, incluyendo el cumplimiento de la normativa; la tasa de actividad, en particular de las mujeres; y, por último, el rendimiento y crecimiento de las empresas.

h. El intercambio de buenas prácticas entre los Estados miembros y los interlocutores sociales.

2. A la vista de las transformaciones en el mundo del trabajo, se debería prestar una atención particular a los elementos siguientes:

a. El tiempo de trabajo y equilibrio entre la vida laboral y la vida privada. Dar orientación para la adopción de enfoques integrados e innovadores encaminados a atender las necesidades de los trabajadores, tanto hombres como mujeres, para la conciliación de la vida laboral, privada y fa-

po separado para los empleados con contratos estables); 2. Empleadores; 3. Trabajadores por cuenta propia; 4 . Miembros de cooperativas de productores; 5 . Trabajadores familiares auxiliares; 6 . Trabajadores que no pueden clasificarse según la situación en el empleo. Puede realizarse un tratamiento estadístico de grupos particulares de trabajadores. Revisión de la Clasificación Internacional de la Situación en el Empleo (CISE-93). Documento para la Discusión. Documento 8, 19. ${ }^{\text {a Conferen- }}$ cia Internacional de Estadísticos del Trabajo, Oficina Internacional del Trabajo, Ginebra, 2013. En esta última revisión, los datos estadísticos del empleo total están desglosados por sexo, y se analizan las diferencias de género significativas en la situación en el empleo de los diversos grupos de trabajadores según la clasificación. Además se fija la tarea de determinar si existen otros grupos que requieran ser identificados por separado. Pág. 53.

${ }_{49}$ Ya en su decisión de marzo de 2005, el Consejo de Administración encomendó incorporar la perspectiva de género en todos los programas y proyectos de cooperación técnica de la OIT a lo largo del ciclo de la vida de los mismos. 
miliar, y utilizar plenamente los convenios pertinentes de la OIT.

b. La extensión de la protección de los trabajadores en las PYMES.

c. La protección efectiva de los trabajadores empleados en las formas atípicas de empleo.

d. El entorno propicio para la protección de los trabajadores superando los obstáculos para la libertad sindical y la negociación colectiva, tanto en la legislación como en la práctica.

e. Las políticas de contratación pública que promuevan la protección de los trabajadores mediante prácticas de contratación responsables y mediante la ratificación del Convenio núm. 94, sobre las cláusulas de trabajo (contratos celebrados por las autoridades públicas $)^{50}$.

f. La protección de los trabajadores en las cadenas mundiales de suministro ${ }^{51}$.

\section{LA RECOMENDACIÓN SOBRE LA TRANSICIÓN DE LA ECONOMÍA INFORMAL A LA ECONOMÍA FORMAL}

Con fecha 12 de junio de 2015, la Conferencia adopta la Recomendación núm. 204, sobre la transición de la economía informal a la economía formal, que incluye un Anexo que recopila los instrumentos adoptados por la OIT y las Naciones Unidas, pertinentes para facilitar dicha transición.

50 Convenio sobre las cláusulas de trabajo (contratos celebrados por las autoridades públicas), núm. 94, adoptado el 29 de junio de 1949.

${ }^{51}$ En junio de 2016, se celebra la Discusión de la 105. a reunión de la Conferencia Internacional del Trabajo, sobre las cadenas mundiales de suministro. La Conferencia aprueba la Resolución relativa al trabajo decente en las cadenas mundiales de suministro, en la que se que pone de manifiesto que es la OIT, debido a su mandato global, experiencia y conocimientos especializados sobre el mundo del trabajo, en colaboración con sus Miembros, la mejor posicionada para liderar la acción mundial en favor del trabajo decente en las cadenas mundiales de suministro y se definen las responsabilidades que tienen los gobiernos, las empresas y los interlocutores sociales en la promoción del trabajo decente y en la protección de estos trabajadores. Resolución relativa al trabajo decente en las cadenas mundiales de suministro, Conferencia Internacional del Trabajo, 105. ${ }^{\circ}$ reunión, Ginebra, 2016, puntos 14 y 15. 
La expresión economía informal hace referencia a todas las actividades económicas desarrolladas por los trabajadores y las unidades económicas que, en la legislación o en la práctica, están insuficientemente cubiertas por sistemas formales o no lo están en absoluto y no abarca las actividades ilícitas ${ }^{52}$.

En el amplio informe de la OIT del año 2012 sobre los principios y derechos fundamentales en el trabajo, la Conferencia ya ponía de manifiesto que la mayoría de los trabajadores de la economía informal no gozan de los principios y derechos fundamentales en el trabajo ${ }^{53}$.

Los trabajadores de la economía informal tienen como rasgo en común la vulnerabilidad de sus derechos y de su situación económica. Realizan sus actividades fuera del ámbito de la aplicación formal de la ley o, por alguna razón, ésta no se aplica para protegerles y, como consecuencia, no pueden disfrutar ni defender sus derechos fundamentales en el trabajo.

La economía informal incluye tanto lo que se conoce como sector informal, como el empleo informal en los establecimientos del sector formal. Esto implica que, cuando la legislación nacional no regula suficientemente ciertas formas de empleo atípicas, los trabajadores considerados pueden verse sujetos a condiciones de informalidad. De hecho, se ha registrado un aumento considerable de la informalidad dentro del sector formal de muchos países, incluidos los industrializados, entre otras causas por el debilitamiento de la relación de trabajo y la falta de vigilancia del cumplimiento de la legislación laboral.

La economía informal es muy diversa y afecta a todos los sectores. Aunque la agricultura es el sector más afectado, especialmente en los países en desarrollo, la informalidad se detecta también en la industria electrónica, la construcción, los textiles, el turismo, el transporte o los servicios domésticos. El informe advierte de la gradación de vínculos entre el empleo formal y el informal, particularmente en las cadenas de producción.

${ }^{52}$ Recomendación sobre la transición de la economía informal a la economía formal, núm. 204, adoptada el 12 de junio de 2015, párrafo I.

${ }_{53}$ Principios y derechos fundamentales en el trabajo: del compromiso a la acción. Informe VI. Discusión recurrente en el marco de la Declaración de la OIT sobre la justicia social para una globalización equitativa y con arreglo al seguimiento de la Declaración de la OIT relativa a los principios y derechos fundamentales en el trabajo, Conferencia Internacional del Trabajo, 101. reunión, Oficina Internacional del Trabajo, Ginebra, 2012, págs. 41-43 
Las violaciones más flagrantes de los principios y derechos en el trabajo ocurren generalmente en la economía informal. En primer lugar, se registran altas tasas de discriminación. Tanto en países industrializados como en los países en desarrollo, son los jóvenes, las mujeres y los migrantes los que más la sufren. Además, la diferencia de ingresos entre los trabajadores formales e informales es más marcada en el caso de las mujeres. Por otra parte, en la mayoría de los países la tasa de sindicación de trabajadores informales es muy baja y no tienen posibilidad real de ejercer el derecho de negociación colectiva. Pero sin duda, el mayor problema que conlleva, es que en ella se recurre de forma desproporcionada al trabajo infantil y al trabajo forzoso.

La OIT concluye que la pobreza es una causa determinante de la informalidad: "Las personas que se enfrentan a discriminación directa o indirecta y no disfrutan de igualdad de oportunidades y de trato -ya sea en términos de acceso a la educación y a la formación, a los recursos o a los trabajos formales- acaban incorporándose a la economía informal, normalmente en el extremo más bajo y en los peores empleos ${ }^{54}$.

Los datos estadísticos de trabajadores ocupados en la economía informal son alarmantes. Constituyen el grueso de la masa laboral mundial y se concentran en países menos desarrollados, principalmente en África y Asia Meridional, donde representa el 90 por 100 de la fuerza del trabajo ${ }^{55}$.

La reciente Recomendación sobre la transición de la economía informal a la economía formal, reconoce su alta incidencia y el obstáculo que representa para la garantía de los principios y derechos en el trabajo y la protección social. La mayoría de las personas que se in-

${ }^{54}$ El trabajo decente y la economía informal, Informe $V$, Conferencia Internación del Trabajo. 90. ${ }^{\mathrm{a}}$ reunión, Oficina Internacional del Trabajo, Ginebra, 2002, pág. 45.

55 Conclusiones sobre el trabajo decente en la economía informal, Conferencia Internacional del Trabajo, 90. ${ }^{a}$ reunión, Ginebra, 2002, párrafo 3. Tampoco los últimos informes de la OIT sobre perspectivas sociales y de empleo en el mundo son alentadores. La mala calidad del trabajo sigue siendo un grave problema. El empleo vulnerable alcanza a 1,5 mil millones de personas, más del 46 por ciento del empleo mundial, y existen importantes diferencias por género; las mujeres siguen teniendo más riesgo de empleo vulnerable que los hombres. Perspectivas sociales y de empleo en el mundo. Tendencias 2016. Resumen y tendencias sociales y del empleo en el mundo, Organización Internacional del Trabajo, Ginebra, 2016, págs. 7 y 8 . Sobre datos estadísticos de economía informal se puede consultar: Medición de la economía informal. Dificultades estadísticas, Oficina Internacional del Trabajo, Ginebra, y La medición de la informalidad: Manual estadístico sobre el sector informal y el empleo informal, Oficina Internacional del Trabajo, Ginebra, 2013. 
corporan a la economía informal no lo hacen por propia elección, sino como consecuencia de la falta de oportunidades en la economía formal y por carecer de otros medios de sustento. Esta transición es esencial para alcanzar un desarrollo incluyente y hacer efectivo el trabajo decente para todos ${ }^{56}$.

Entre los principios primordiales que los Miembros deberían valorar al formular sus estrategias, se postula la promoción y la protección efectiva de los derechos humanos de todas las personas ocupadas en la economía informal, el respeto de los principios y derechos fundamentales en el trabajo, la promoción de la igualdad de género y la no discriminación, la necesidad de prestar especial atención a los grupos particularmente vulnerables, entre ellos las mujeres, la prevención y sanción de las conductas que tratan de evitar la economía formal con el fin de evadir el pago de impuestos y el cumplimiento de la legislación social y laboral ${ }^{57}$.

Respecto a la protección social, es importante la adopción inmediata de medidas para eliminar las condiciones inseguras e insalubres que a menudo caracterizan estos empleos, promover la protección de la seguridad y salud en el trabajo, y extenderla a todos los empleadores y trabajadores. Asimismo, se tendría que ampliar progresivamente, en la legislación y en la práctica, la seguridad social, la protección de la maternidad y el salario mínimo.

Como medidas específicas se recomienda que al establecer y mantener pisos nacionales de protección oficial en el marco de sus sistemas de seguridad social, se valoren las necesidades y circunstancias de estos trabajadores y sus familias. Los servicios de guardería y de atención a la persona de calidad y económicamente asequibles, promueven la igualdad de género en los ámbitos de emprendimiento y de las oportunidades de empleo y facilitan el paso a la economía formal ${ }^{58}$.

${ }^{56}$ Recomendación sobre la transición de la economía informal a la economía formal, núm. 204, adoptada el 12 de junio de 2015, Preámbulo. Para un estudio sobre el trabajo informal y la Recomendación núm. 204 y sobre el género y el trabajo informal véase: Monereo Pérez Díaz, J. L., y PERÁn Quesada, S., Derecho social y trabajo informal: implicaciones laborales, económicas y de Seguridad Social del fenómeno del trabajo informal y de la economía sumergida, Editorial Comares, Granada, 2016, págs. 3-26 y págs. 167-193.

57 Recomendación sobre la transición de la economía informal a la economía formal, núm. 204, adoptada el 12 de junio de 2015, párrafo 7.

58 Recomendación sobre la transición de la economía informal a la economía formal, núm. 204, adoptada el 12 de junio de 2015, párrafos 1 a 21. 


\section{LOS CUATRO ÁMBITOS DE LA PROTECCIÓN DE LOS TRABAJADORES. CONSIDERACIONES RELACIONADAS CON LA IGUALDAD DE GÉNERO}

\section{Salarios}

Las políticas deben ir dirigidas a la fijación de los sueldos de conformidad con el Convenio 131 y Recomendación 135, sobre la fijación de salarios mínimos ${ }^{59}$, que tienen que ofrecer una protección adecuada a todos los trabajadores sujetos a una relación de trabajo independientemente de su tipo de contrato y con inclusión de las mujeres, los jóvenes y los trabajadores migrantes.

El hecho de que los países cuenten con instituciones adecuadas para la fijación de los salarios mínimos debería servir también para hacer frente al aumento de las desigualdades, en particular entre hombres y mujeres, mediante la promoción del derecho a la igualdad de remuneración por un trabajo de igual valor ${ }^{60}$.

La protección efectiva de los trabajadores también exige el pago regular e íntegro del salario, la documentación del pago y mecanismos efectivos de recurso para que los trabajadores recuperen las pagas no abonadas.

Como medida para promover la igualdad de género en el lugar de trabajo, la OIT ya apuntó la elaboración de políticas para reducir la disparidad salarial entre los hombres y las mujeres basadas en el seguimiento sistemático de los cambios en el mundo del trabajo, la organización de las estructuras laborales y las causas de desigualdad en la remuneración. En caso de existir una elevada incidencia de salarios bajos, se debería valorar la posibilidad de establecer una política de salario mínimo eficaz que incorporase la perspectiva de género. En países con una elevada tasa de economía informal y

${ }^{59}$ Convenio sobre la fijación de salarios mínimos, núm. 131, adoptado el 22 de junio de 1970. Recomendación sobre la fijación de salarios mínimos, núm. 135, adoptada el 22 de junio de 1970.

60 Véase Convenio núm. 100, relativo a la igualdad de remuneración entre la mano de obra masculina y la mano de obra femenina por un trabajo de igual valor, adoptado el 23 de mayo de 1953 y Recomendación núm. 90, sobre la igualdad de remuneración entre la mano de obra masculina y la mano de obra femenina por un trabajo de igual valor, adoptada el 29 de junio de 1951.

Los informes de la OIT siguen reflejando las desigualdades salariales de género. Informe Mundial sobre Salarios 2014/2015. Salarios y desigualdad de ingresos, Organización Internacional del Trabajo, Ginebra, 201, parte II, Sección 10, Disparidad de salarios, págs. 50-63. 
marcada diferenciación de acceso a los trabajos en función del género, podría resultar más eficaz un sistema de clasificación por ocupaciones y de evaluación de los puestos de trabajos sin perjuicios de género ${ }^{61}$.

\section{Tiempo de trabajo}

La reglamentación de las condiciones del tiempo de trabajo debe fijar las horas de trabajo, incluida la duración máxima de la jornada y de la semana laboral para todos los empleados, independientemente del tipo de relación de trabajo. Las políticas deben ir encaminadas a la reducción de los horarios prolongados y a la ordenación de las horas de trabajo ${ }^{62}$.

Estas medidas mejoran la salud y la seguridad de los trabajadores, el equilibrio entre la vida laboral y privada y, por ende, la productividad de las empresas.

También la flexibilización de los horarios ayuda a valorar las necesidades de cada trabajador y a la conciliación de la vida laboral y familiar.

La regulación del trabajo a tiempo parcial tiene que garantizar un trato igual al de los trabajadores a tiempo completo en situación comparable en lo referente al empleo, salario y condiciones de trabajo de conformidad con el Convenio 175, sobre el trabajo a tiempo parcial.

\section{Seguridad y salud en el trabajo}

Los accidentes y enfermedades relacionadas con el trabajo tienen consecuencias negativas tanto para los trabajadores como para sus familias y afectan igualmente a la productividad y competitividad de las empresas y a la calidad de empleo. Ocasionan costes para los hogares y los gobiernos, interfieren en el crecimiento económico y pue-

${ }^{61}$ La igualdad de género como eje del trabajo decente, Informe VI, Conferencia Internacional del Trabajo, 98. ${ }^{\circ}$ reunión, Oficina Internacional del Trabajo, Ginebra, 2009, Punto. 415 Capítulo 8. Principales orientaciones de política para las actividades internacionales y nacionales, pág. 196.

62 Véase el Convenio sobre las horas de trabajo (industria), núm. 1, adoptado el 28 de noviembre de 1919, instrumento en situación provisoria; Convenio sobre las cuarenta horas, núm. 47, adoptado el 22 de junio de 1935, instrumento en situación provisoria y Recomendación sobre la reducción de la duración del trabajo, núm. 116, adoptada el 26 de junio de 1962. 
den causar daños irreparables en el medio ambiente. De igual manera, la adopción de medidas para la seguridad y la salud, afectará a estos mismos agentes económicos pero de forma inversa ${ }^{63}$.

Las organizaciones de empleadores y de trabajadores reconocen la relevancia de la prevención. Los riesgos deben ser gestionados y controlados y los sistemas de gestión de la seguridad y salud en el trabajo son fundamentales para poder evitar los accidentes de trabajo y los trastornos de la salud. El estudio general de la OIT relativo al Convenio núm. 155, sobre seguridad y salud de los trabajadores de 1981, realizado en el año 2009 por la Comisión de Expertos en Aplicación de Convenios y Recomendaciones, evidenciaba que un gran número de países en desarrollo estaban actualizando sus políticas nacionales sobre seguridad y salud en el trabajo y sus sistemas normativos y de control de la aplicación ${ }^{64}$.

No obstante, la OIT advierte que en la práctica, muchas legislaciones nacionales solamente dan cobertura parcial y que el cumplimiento de aquellas que dan una cobertura más amplia, es difícil. Tampoco se aplican las estrategias de prevención para anticipar, identificar, evaluar y controlar los riesgos existentes y los emergentes. En particular, esto ocurre en el caso de los riesgos relacionados con el género y en el caso de las PYMES ${ }^{65}$.

Las transformaciones en el mundo del trabajo y las tendencias del empleo en las últimas décadas han contribuido a la aparición de nuevos riesgos para los trabajadores, como los derivados del uso de productos químicos, los problemas psicosociales o el acoso laboral ${ }^{66}$.

${ }_{63} \mathrm{Al}$ respecto puede consultarse La prevención de las enfermedades profesionales, Organización Internacional de Trabajadores, Suiza, 2013; informe de la celebración del Día Mundial de la Seguridad y Salud en el Trabajo, que expone en líneas generales la situación actual en relación con las enfermedades profesionales y presenta propuestas para abordar el grave déficit de trabajo decente que representa.

${ }^{64}$ Informe III (Parte 1B) Estudio general relativo al Convenio sobre seguridad y salud de los trabajadores, 1981 (núm. 155), a la Recomendación sobre seguridad y salud de los trabajadores, 1981(núm. 164), y al Protocolo de 2002 relativo al Convenio sobre seguridad y salud de los trabajadores, 1981, Informe de la Comisión de Expertos en Aplicación de Convenios y Recomendaciones (artículos 19, 22 y 35 de la Constitución), Oficina Internacional del Trabajo, Ginebra, 2009, pág. 12.

${ }^{65}$ Discusión recurrente sobre el objetivo estratégico de la protección social (protección de los trabajadores) con arreglo al seguimiento de la Declaración de la OIT sobre la justicia social para una globalización equitativa, de 2008 y Conclusiones relativas al a discusión recurrente sobre la protección social (protección a los trabajadores), Conferencia Internacional del Trabajo, 104. a reunión, Ginebra, 2015, punto 16, pág. 6.

${ }^{66}$ Los riesgos nuevos y emergentes en el trabajo pueden ser provocados por la innovación técnica o por el cambio social u organizativo; véase, por ejemplo, el informe del Día Mundial sobre Seguridad y Salud en el Trabajo 2010, Riesgos emergentes 
También han experimentado cambios muy importantes los perfiles de edad y género en la fuerza de trabajo. La falta de protección de los nuevos riesgos es mayor en el empleo precario y en la economía informal y son las mujeres las que se han visto más afectadas como grupo vulnerable.

En nuestra opinión, dos obstáculos se deben superar para garantizar la protección de la seguridad y salud efectiva de las mujeres en el trabajo.

En primer lugar, la falta de perspectiva de género en las estrategias de prevención y elaboración de políticas. El Informe de la OIT del Día Mundial sobre Seguridad y Salud en el Trabajo del año 2010 sobre los riesgos emergentes y modelos de prevención, señala que el análisis de la dimensión de género en la protección de los trabajadores es imprescindible para las estrategias de prevención y de formulación de políticas ${ }^{67}$.

Se deberían valorar los efectos que producen sobre la salud los roles que nuestra sociedad tiene asignados en función del género y la relación que existe entre el papel social y económico que desempeñan los hombres y las mujeres actualmente y la salud en el trabajo. Los puntos de vista que tienen en cuenta la perspectiva del género, permiten que las diferencias sean más visibles y ayudan a identificar y afrontar problemas concretos.

Las medidas generales en materia de seguridad y salud dirigidas a todos los empleados no siempre contemplan los beneficios deseados para las condiciones de trabajo específicas de las mujeres. Deberían realizarse estudios en profundidad de los riesgos en las ocupaciones

y nuevos modelos de prevención en un mundo de trabajo en transformación, Organización Internacional del Trabajo, Suiza, 2010, pág. 5 y también La Seguridad y Salud en el uso de productos químicos en el trabajo, Organización Internacional del Trabajo, Ginebra, 2013; informe de la celebración del Día Mundial de la Seguridad y la Salud en el Trabajo de 2014 que presenta los elementos para el establecimiento de programas a nivel nacional y empresarial que contribuyen a garantizar la gestión racional de los productos químicos en el trabajo. Sobre la política de la OIT sobre riesgos psicosociales y la importancia del concepto del trabajo decente, BALLESTER PASTOR, M A., "La política de la OIT y de la Unión Europea sobre salud y riesgos psicosociales», Revista Internacional y Comparada de Relaciones laborales y Derecho del Empleo, vol. 1, núm. 4, 2013, págs. 15-16.

${ }_{67}$ Riesgos emergentes y nuevos modelos de prevención en un mundo de trabajo en transformación, Informe del Día Mundial sobre Seguridad y Salud en el Trabajo 2010, Organización Internacional del Trabajo, Suiza, 2010, págs. 12-13. 
en las que predominan, y fomentar políticas y prácticas diferenciadas en función del género cuando corresponda ${ }^{68}$.

En segundo lugar, la escasa intervención de las mujeres en la toma de decisiones y en la elaboración de políticas y normas sobre seguridad y salud en el trabajo, ha introducido un sesgo de género en la indemnización por sus lesiones y enfermedades. Sólo podremos observar cambios positivos en las políticas y prácticas nacionales en materia de salud y seguridad en el lugar de trabajo si aseguramos que tanto las mujeres como los hombres participen en las decisiones que les afectan ${ }^{69}$.

\section{Protección de la maternidad}

La protección de la maternidad en el trabajo tiene como objetivos básicos preservar la salud de la madre y del recién nacido y proporcionar una medida de seguridad económica y de empleo a la madre y a su familia. Es una responsabilidad de carácter colectivo y sus beneficios redundan en la sociedad en su conjunto. Ayuda a mejorar la salud materna e infantil, fomenta la tasa de actividad de las mujeres y contribuye al crecimiento económico y a la erradicación de la pobreza.

Se trata, además, de un derecho fundamental de la mujer en edad de procrear y es esencial para la igualdad de oportunidades y para lograr la igualdad de género en el mundo laboral. Se ha proclamado en el Pacto Internacional de Derechos Económicos, Sociales y Culturales (CESCR), la Convención sobre la Eliminación de Todas las Formas de Discriminación contra la Mujer (CEDAW) y la Convención sobre los derechos del Niño (CRC); forma parte integral del Programa de Trabajo Decente y contribuye al logro de los objetivos de desarrollo sostenible fijados por Naciones Unidas en su Agenda 2030.

${ }^{68}$ La igualdad de género como eje del trabajo decente, Informe VI, Conferencia Internacional del Trabajo, 98. ${ }^{\circ}$ reunión, Oficina Internacional del Trabajo, Ginebra, 2009, Punto. 415 Capítulo 8. Principales orientaciones de política para las actividades internacionales y nacionales, pág. 196.

${ }^{69}$ Realizing the right of women to safe work. Building gender equality into occupational safety and health, governance. M Cornish; nota conceptual de la OIT para el XVIII Congreso Mundial sobre Seguridad y Salud en el Trabajo de 2008, Seúl (OIT Ginebra, 2008). Como referencia en La igualdad de género como eje del trabajo decente, Informe VI, Conferencia Internacional del Trabajo, 98. ${ }^{a}$ reunión. Oficina Internacional del Trabajo, Ginebra, 2009, Punto 312, pág. 157. 
La OIT señala como partes responsables e implicadas en la protección de la maternidad a los gobiernos, las organizaciones de empleadores y trabajadores, la sociedad civil y las universidades y centros de investigación ${ }^{70}$.

Las normas internacionales han ido ampliando el ámbito de la protección de la maternidad a lo largo de los años. Los instrumentos más recientes de la OIT son el Convenio núm. 183 y la Recomendación núm. 191, sobre protección de la maternidad, adoptados el año 2000 y que, a pesar de su escasa ratificación, proporcionan una amplia orientación para la legislación y la práctica nacionales ${ }^{71}$.

Sin embargo, son en realidad las organizaciones internacionales intergubernamentales, como la Unión Africana, la Unión Europea o la Organización de Estados Americanos, las que cuentan con legislación más detallada y protectora al estar proyectadas para un contexto regional específico con condiciones económicas y sociales similares entre los estados. Y, entre ellas, es la Unión Europea la organización que más ha avanzado en esta materia y sus disposiciones son las más amplias y novedosas sobre protección de la maternidad y las responsabilidades familiares.

La OIT señala como elementos centrales de la protección de la maternidad en el trabajo los siguientes: la licencia de maternidad, la licencia de paternidad y la licencia parental; las prestaciones pecuniarias y médicas; la protección de la salud en el lugar de trabajo; la pro-

${ }^{70}$ Protección de la maternidad en el trabajo. ¿Quiénes son las partes interesadas? Kit de recursos sobre la protección de la maternidad. Del anhelo a la realidad para todos. Módulo 4, Organización Internacional del Trabajo, Servicio sobre las Condiciones de Trabajo y del Empleo (TRAVAIL), Ginebra, 2012.

${ }_{71}$ Los instrumentos normativos sobre protección de la maternidad, aprobados hasta la fecha por OIT son: el Convenio núm. 3, relativo al empleo de las mujeres antes y después del parto, adoptado el 29 de noviembre de 1919; el Convenio núm. 103, sobre la protección de la maternidad (revisado), adoptado el 28 de junio de 1952, la Recomendación núm. 95, sobre la protección de la maternidad, adoptada el 28 de junio de 1952; el Convenio núm. 183, relativo a la revisión del Convenio sobre la protección de la maternidad (revisado), adoptado el 15 de junio de 2000 y Recomendación núm. 191, relativa a la revisión de la Recomendación sobre la protección de la maternidad (revisada), adoptada el 15 de junio de 2000.

Para un análisis de los Convenios y Recomendaciones adoptados hasta la fecha por la OIT sobre protección de la maternidad y de sus repercusiones en el ordenamiento jurídico español y en la OIT, véase BALLESTER PASTOR, M. A., «Pasado y presente de la protección de la maternidad en los convenios de la OIT y en España», Revista española de desarrollo y cooperación, Universidad Complutense de Madrid, n. ${ }^{\circ}$ 34, 2014, págs. 75-87, y BALlester PASTOR, M. A., «Protección de la maternidad y protección de la mujer en la OIT: avances y contradicciones». Revista del Ministerio de Empleo y Seguridad Social, n. ${ }^{\circ} 117,2015$, págs. 75-105. 
tección del empleo y la no discriminación ${ }^{72}$, y el tiempo y dispositivos para la lactancia.

Con carácter general las mujeres que trabajan en el sector formal de la economía son las únicas que se benefician de la protección de la maternidad. Sin embargo, todas las mujeres, incluidas las que participan en las formas atípicas de empleo, deberían contar con protección como establece el Convenio núm. 183, sobre protección de la maternidad. Por eso, la OIT tiene como objetivo no sólo reforzar la protección de la maternidad en todos sus ámbitos sino también ampliarla a todas las mujeres que trabajan en los distintos sectores de la economía.

Los países deben contar con una legislación nacional clara y exhaustiva sobre la protección de la maternidad en el trabajo y realizar un amplio análisis de su aplicación.

Para poder subsanar las deficiencias en materia de cobertura es necesario diseñar y aplicar estrategias viables, incluida la adaptación de los lugares de trabajo y la extensión gradual de la protección a todas las trabajadoras.

La financiación de las prestaciones de maternidad mediante los impuestos generales o la seguridad social en lugar de asignar esa responsabilidad al empleador puede disminuir la discriminación en la contratación de mujeres ${ }^{73}$.

En el momento en que la mujer se reincorpora al trabajo tras la interrupción del mismo por nacimiento o licencia de maternidad, las medidas de apoyo a los padres para conciliar el trabajo con sus responsabilidades familiares son esenciales para la salud y el desarrollo del niño. Suponen, en realidad, un beneficio a las familias, a las empresas y a la sociedad. El Convenio núm. 156 y la Recomendación núm. 165, sobre trabajadores con responsabilidades familiares, orien-

72 Véase Convenio núm. 111, sobre la discriminación (empleo y ocupación), adoptado el 25 de junio de 1958 y la Recomendación que le acompaña, Recomendación núm. 111, sobre la discriminación en materia de empleo y ocupación, adoptada el 25 de junio de 1958.

${ }^{73}$ Discusión recurrente sobre el objetivo estratégico de la protección social (protección de los trabajadores) con arreglo al seguimiento de la Declaración de la OIT sobre la justicia social para una globalización equitativa, de 2008 y Conclusiones relativas al a discusión recurrente sobre la protección social (protección a los trabajadores), Conferencia Internacional del Trabajo, 104. ${ }^{\text {a }}$ reunión, Ginebra, 2015, punto 18, pág. 7. Postura ya defendida por la OIT desde hace tiempo. La igualdad de género como eje del trabajo decente, Informe VI, Conferencia Internacional del Trabajo, 98. ${ }^{\circ}$ reunión, Oficina Internacional del Trabajo, Ginebra, 2009, punto 109, pág. 56. 
tan sobre la adopción de políticas y medidas para la conciliación de la vida laboral y familiar ${ }^{74}$.

Las licencias de paternidad y parental, además de ayudar a la conciliación del trabajo y la familia, fomentan la corresponsabilidad de las tareas entre mujeres y hombres. En particular, la regulación de la licencia parental está contribuyendo a la aceptación del reparto equitativo de responsabilidades familiares y al reconocimiento de que tanto las madres como los padres son responsables del cuidado de sus hijos. La licencia parental no se contempla en ningún convenio de la OIT, pero sí se menciona en las Recomendaciones núms. 165 y $191^{75}$.

La OIT recomienda como medida de protección social que promueve la igualdad de género en el trabajo, la mejora de los sistemas nacionales de seguridad social, para que sean incluyentes, no discriminatorios y tengan en cuenta las necesidades de los trabajadores con responsabilidades familiares ${ }^{76}$.

A pesar de las escasas suscripciones que hay de los tres Convenios sobre maternidad, la gran mayoría de los Miembros han adoptado normas sobre protección de la maternidad en el trabajo y medidas de ayuda a los trabajadores con responsabilidades familiares. Los Convenios, ratificados o no, han tenido una gran influencia internacional y en los últimos años la legislación de la protección de la maternidad ha registrado una notable mejora.

En el año 2014 la OIT publica un estudio que examina la legislación y la práctica a nivel nacional en materia de maternidad y paternidad en el trabajo en 185 países y territorios, y las compara con los instrumentos normativos de la Organización. Según los datos del informe, el 34 por ciento de los países cumple con tres de los requisitos

${ }^{74}$ Convenio núm. 156, sobre la igualdad de oportunidades y de trato entre trabajadores y trabajadoras: trabajadores con responsabilidades familiares, adoptado el 23 de junio de 1981 y Recomendación núm. 165, sobre la igualdad de oportunidades y de trato entre trabajadores y trabajadoras: trabajadores con responsabilidades familiares, adoptada el 23 de junio de 1981.

${ }^{75}$ Sin embargo, la Directiva de la Unión Europea que regula el permiso parental está siendo decisiva y está promoviendo y alentando a los padres a hacer uso de esta licencia. Directiva 2010/18/UE del Consejo, de 8 de marzo de 2010, por la que se aplica el Acuerdo marco revisado sobre el permiso parental, celebrado por BUSINESSEUROPE, la UEAPME, el CEEP y la CES, y se deroga la Directiva 96/34/CE (DO L 68, 18.3.2010, págs. 13-20).

${ }^{76}$ La igualdad de género como eje del trabajo decente, Informe VI, Conferencia Internacional del Trabajo, 98. ${ }^{\mathrm{a}}$ reunión, Oficina Internacional del Trabajo, Ginebra, 2009, Punto 415, Capítulo 8: Principales orientaciones de política para las actividades internacionales y nacionales, pág. 196. 
que considera esenciales: la licencia de maternidad de al menos 14 semanas, las remuneraciones para la trabajadora no inferiores a dos tercios de las que venía percibiendo y la financiación del coste mediante un seguro social o con cargos a fondos públicos ${ }^{77}$.

Pese a ello, la gran mayoría de las trabajadoras del mundo, alrededor de 830 millones, no disfrutan de suficiente protección de la maternidad y 750 millones carecen de ella ${ }^{78}$.

${ }^{77}$ La maternidad y la paternidad en el trabajo. La legislación y la práctica en el mundo, Servicio de Género, Igualdad y Diversidad, Departamento de Condiciones de Trabajo e Igualdad. Organización Internacional de Trabajadores, Ginebra, 2014. El estudio se basa en el informe de la OIT Maternity and paternity at work. Law and practice across the world, OIT, Ginebra, 2014. Se trata de una revisión de dos ediciones anteriores de los años 2005 y 2010, con datos recogidos por la OIT desde 1994. La maternidad en el trabajo. Examen de la legislación nacional. Resultados de la Base de datos de la OIT sobre las leyes relacionadas a las condiciones de trabajo y del empleo, 2. ${ }^{2}$ ed., OIT, Ginebra, 2010.

78 «Si bien prácticamente todos los países proporcionan algunas formas de protección de maternidad a las mujeres empleadas, cerca del 60 por ciento de las mujeres trabajadoras en todo el mundo (casi 750 millones de mujeres) no se benefician del derecho legal a la licencia de maternidad. Los problemas que plantea la puesta en práctica, la concienciación acerca de los derechos, la insuficiente capacidad contributiva, las prácticas discriminatorias, la informalidad y la exclusión social significan que, en todo el mundo, apenas 330 millones de mujeres trabajadoras (28,2 por ciento) recibirían prestaciones pecuniarias contributivas o no contributivas en caso de parto. La existencia de grandes regímenes de protección social no contributivos pueden, en cierta medida, compensar tanto las tasas más bajas de participación de las mujeres en el mercado de trabajo como sus condiciones de empleo menos favorables por lo referente a la cobertura de protección social. Sin embargo, los niveles de las prestaciones no contributivas suelen ser modestos, y por lo general no bastan para que las mujeres y sus hijos, y también las mujeres de edad, superen el umbral de la pobreza, especialmente a falta de atención de salud esencial». Las mujeres en el trabajo. Tendencias de 2016. Resumen ejecutivo, Organización Internacional del Trabajo, Ginebra, pág. 9. 
